\title{
Is glaucoma associated with an increased risk of cataract?
}

\author{
Esmeralda V M J Kuppens, Jaap A van Best, Caesar C Sterk
}

\begin{abstract}
Aims-The risk of developing cataract in patients with untreated glaucoma or with ocular hypertension was evaluated by comparing the values of lenticular autofluorescence and light transmission in 16 patients with primary open angle glaucoma and 22 patients with ocular hypertension with those of 24 healthy controls.

Methods-Increase of lenticular autofluorescence and decrease of transmission values in comparison with controls were considered to be precursors of cataract. The values of both variables were determined by fluorophotometry. Each value was normalised for age by dividing it by the value for a healthy control of the same age.

Results-The mean age normalised autofluorescence and transmission values of all patients did not differ significantly from those of the controls (difference $<5 \% ; p=0.6$ and $p=0.2$, respectively). Also the mean age normalised autofluorescence and transmission values between glaucoma and ocular hypertension patients did not differ significantly $(p=0.8$ and $p=0.9$, respectively).

Conclusion-The study indicates that untreated primary open angle glaucoma or untreated ocular hypertension do not seem to increase significantly the risk of developing cataract.

(Br f Ophthalmol 1995; 79: 649-652)
\end{abstract}

Primary open angle glaucoma (POAG) and cataract are eye diseases which mainly occur in later life. Both diseases are often diagnosed concurrently in elderly patients which might suggest that the two diseases are more closely related than just by age. Recent case control studies $^{12}$ reported that glaucoma could be considered as a powerful and independent risk factor for the development of cataract. It was pointed out that glaucoma accounted for $5-6 \%$ of all cataracts. However, these studies dealt only with glaucoma patients who had been medically and/or surgically treated. It is known that some of the topical glaucoma drugs ${ }^{3-6}$ and glaucoma filtering surgery ${ }^{4-9}$ can induce or accelerate cataract formation. Therefore, the question whether glaucoma in itself can contribute to an increased risk of cataract remains to be answered. ${ }^{10}$

The crystalline lens contains substances which exhibit fluorescence. ${ }^{11}$ Physiological age related changes in the composition and amount of these fluorophores arise in the lens leading to an increased lenticular autofluorescence and a decreased light transmission value. ${ }^{12}{ }^{13}$ Diabetes ${ }^{14} 15$ as well as extensive exposure to ultraviolet radiation ${ }^{16}$ are other factors acting upon the lens autofluorescence and transmission. Increased lenticular autofluorescence and decreased transmission values with respect to the values of healthy controls are considered to be precursors of cataract formation. ${ }^{141617}$ These lenticular variables can be measured in a few seconds by fluorophotometry with no burden to the patient.

The autofluorescence and transmission values of the ocular lens were evaluated in untreated POAG patients detected in different stages of their disease in order to find out whether glaucoma itself is associated with an increased risk of developing cataract. The lenses of untreated ocular hypertension $(\mathrm{OHT})$ patients were also evaluated in order to analyse the effect of chronically raised intraocular pressure levels on the lens.

\section{Materials and methods}

\section{PATIENTS}

Patients were recruited from the outpatient department of the Leiden University Eye Clinic and healthy controls from coworkers of the clinic and their relatives.

The POAG and OHT patients were selected according to the following criteria: newly detected untreated cases of POAG or OHT; open chamber angles; bilateral intraocular pressure (IOP) values above $21 \mathrm{~mm} \mathrm{Hg}$ based on five diurnal IOP measurements by applanation tonometry. POAG patients had to meet the following criteria as well: glaucomatous visual field defects and glaucomatous cupping of the optic nerve. Patients and healthy controls who had a history of an ophthalmic disease or who had ever used medication known to induce or accelerate cataract formation were excluded from the study.

The study was approved by the medical ethics committee of the Leiden University Hospital and informed consent was obtained from each individual after verbal and written explanation of the nature of the procedure.

\section{MEASUREMENT PROCEDURE AND ANALYSIS}

Fluorophotometric measurements were carried out with the Fluorotron Master (Coherent Radiation Inc; Palo Alto, CA, USA) fitted with a special lens (anterior segment adaptor) in order to obtain an adequate 


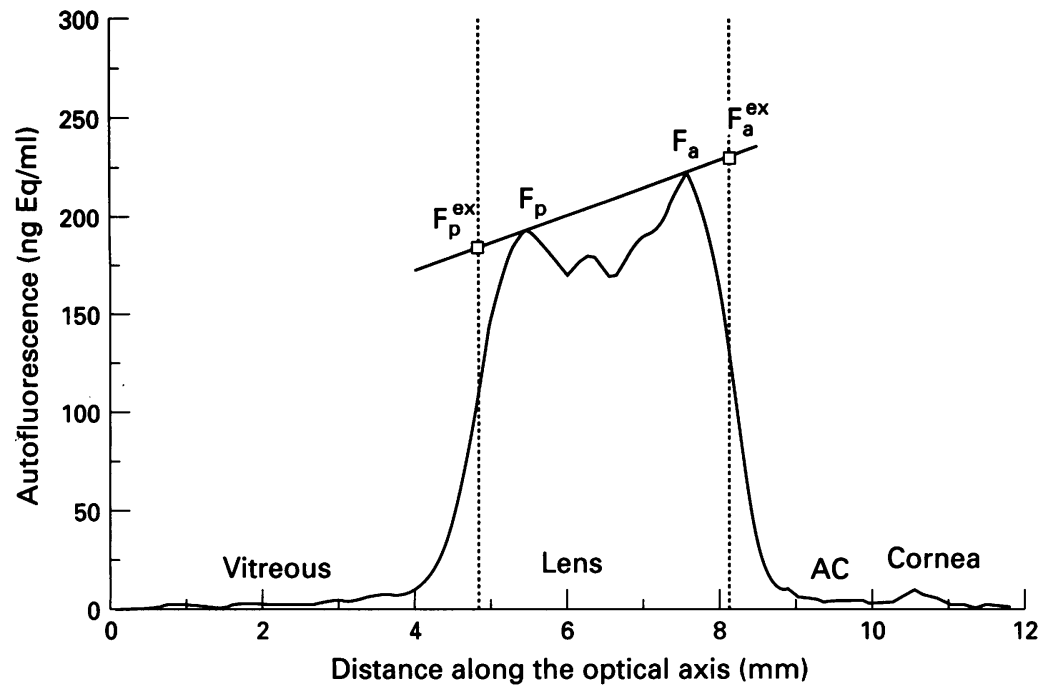

Figure 1 Fluorophotometric scan of the lenticular autofluorescence of an untreated open angle glaucoma patient. The broken vertical lines correspond with the lenticular surfaces; $A C=$ anterior chamber; $F_{\mathrm{a}}=$ anterior autofluorescence peak; $F_{\mathrm{p}}=$ posterior autofluorescence peak; $F_{\mathrm{a}}{ }^{\mathrm{ex}}=$ extrapolated anterior autofluorescence peak; $F_{\mathrm{p}} \mathrm{ex}=$ extrapolated posterior autofluorescence peak.

spatial resolution when measuring the anterior segment of the eye. Four fluorophotometric scans of each crystalline lens were performed. After scanning, the IOP was measured in all patients by applanation tonometry. Figure 1 presents an example of a scan, showing the fluorescence profile of the human crystalline lens. The lens autofluorescence was determined from the four scans of each eye according to a method described previously. ${ }^{18}$ The distance measured along the optical axis was corrected for nonlinearity. A straight line was drawn through the posterior and anterior peaks of the lens (Fig 1). The intercept of this line and a vertical line at half height of the anterior peak was supposed to represent the actual value of the peak anterior autofluorescence $\left(\mathrm{F}_{\mathrm{a}}\right.$ extrapolated $\left.=F_{a}{ }^{e x}\right)$. The intercept of the straight line and a vertical line at half height of the posterior peak was supposed to represent the actual posterior peak autofluorescence $\left(F_{p}\right.$ extrapolated $\left.=F_{p}{ }^{e x}\right)$. The lens transmission $T$ was calculated by the equation ${ }^{12}$ : $\mathrm{T}=\left(\mathrm{F}_{\mathrm{p}} \mathrm{ex} / \mathrm{F}_{\mathrm{a}}{ }^{\mathrm{ex}}\right)^{1 / 2}$.

The autofluorescence and transmission values were normalised for age dependency by taking the ratios between the measured values of each participant and the calculated values for healthy controls of the same age. The autofluorescence values for healthy controls were calculated using a linear function of age $(\mathrm{F}=-98 \cdot 9+10 \cdot 2 \cdot$ age; age in years; $\mathrm{F}$ in $\mathrm{ng}$ equivalent fluorescein $/ \mathrm{ml}$ ) and the transmission values using an exponential function of age $\left(T=1 \cdot 017 \cdot\left(1-\mathrm{e}^{((\text {age }-116) / 32 \cdot 9)}\right) ;\right.$ age in years). The variables in both functions were

Table 1 Data of participants

\begin{tabular}{llllll}
\hline & $\begin{array}{l}\text { No of } \\
\text { patients }\end{array}$ & $\begin{array}{l}\text { Mean age } \\
\text { (years (SD)) }\end{array}$ & $\begin{array}{l}\text { Autofluorescence } \\
(\text { mean }(S D))\end{array}$ & $\begin{array}{l}\text { Transmission } \\
(\text { mean }(S D))\end{array}$ & $\begin{array}{l}\text { Mean IOP } \\
(\text { mm Hg (SD)) }\end{array}$ \\
\hline POAG & 16 & $59(13)$ & $1.06(0.27)$ & $0.96(0.08)$ & $27(4)$ \\
OHT & 22 & $58(13)$ & $1.04(0.25)$ & $0.96(0.09)$ & $27(5)$ \\
HC & 24 & $60(14)$ & $1.01(0.25)$ & $1.00(0.14)$ & - \\
\hline
\end{tabular}

POAG = primary open angle glaucoma; $\mathrm{OHT}=$ ocular hypertension; $\mathrm{HC}=$ healthy controls; IOP=intraocular pressure. obtained by a weighted linear regression analysis and a least square approximation, respectively, to the data points of the healthy controls.

\section{STATISTICS}

The mean age normalised autofluorescence and transmission values of patients were compared with those of controls. D'Agostino's test for departure of normality was used for the assessment of a normal distribution. Student's two tailed $t$ test was used for evaluating the significance level.

\section{Results}

\section{LENS AUTOFLUORESCENCE}

The mean lenticular fluorescence of both eyes was calculated for each patient and control since the values of the right and the left eyes were found to be correlated significantly (linear correlation coefficients $r \geqslant 0.9$, $\mathrm{p}<0.001)$. The data and the mean age normalised autofluorescence values of all POAG patients, OHT patients, and healthy controls are presented in Table 1. The values of all patients and controls were distributed normally $(p=0.01)$. The mean age normalised autofluorescence values of POAG and OHT patients did not differ significantly from that of controls $(p=0.6$ and $\mathrm{p}=0 \cdot 7$, respectively). No significant difference in these autofluorescence values was found between the two patient groups $(p=0 \cdot 8)$.

A weighted linear regression analysis, using inverse squared age as weight factor, revealed that the lenticular autofluorescence values of POAG, OHT patients, and controls correlated significantly with age $(r>0.9$, $\mathrm{p}<0.0001)$. The mean increase in autofluorescence as a function of age of POAG (8.9 ng $\left.\mathrm{Eq} \cdot \mathrm{ml}^{-1} \cdot \mathrm{yr}^{-1}\right)$ and OHT patients (8.7 $\mathrm{ng}$ $\mathrm{Eq} \cdot \mathrm{ml}^{-1} \cdot \mathrm{yr}^{-1}$ ) did not differ significantly from the increase of controls (8.5 ng $\mathrm{Eq} \cdot \mathrm{ml}^{-1} \cdot \mathrm{yr}^{-1} ; \mathrm{p}=0.6$ and $\mathrm{p}=0.9$, respectively, see Fig 2). The mean age normalised autofluorescence values did not correlate significantly with the IOP values in both patient groups $(r<-0 \cdot 1, \mathrm{p}<0 \cdot 7)$.

\section{LENS TRANSMISSION}

The mean lenticular transmission value of both eyes was calculated since the values of the right and the left eyes were found to be correlated significantly in all patients and controls $(r \geqslant 0.7, \mathrm{p}<0.001)$. The mean age normalised transmission values of both patient groups and healthy controls are presented in Table 1 . The values of patients and controls were distributed normally $(p=0.01)$. The mean age normalised transmission values of POAG and OHT patients did not differ significantly from that of controls $(p=0.3$ and $p=0.2$, respectively, see Fig 3). Also no significant difference was found in these values between POAG and OHT patients $(p=0.9)$. 


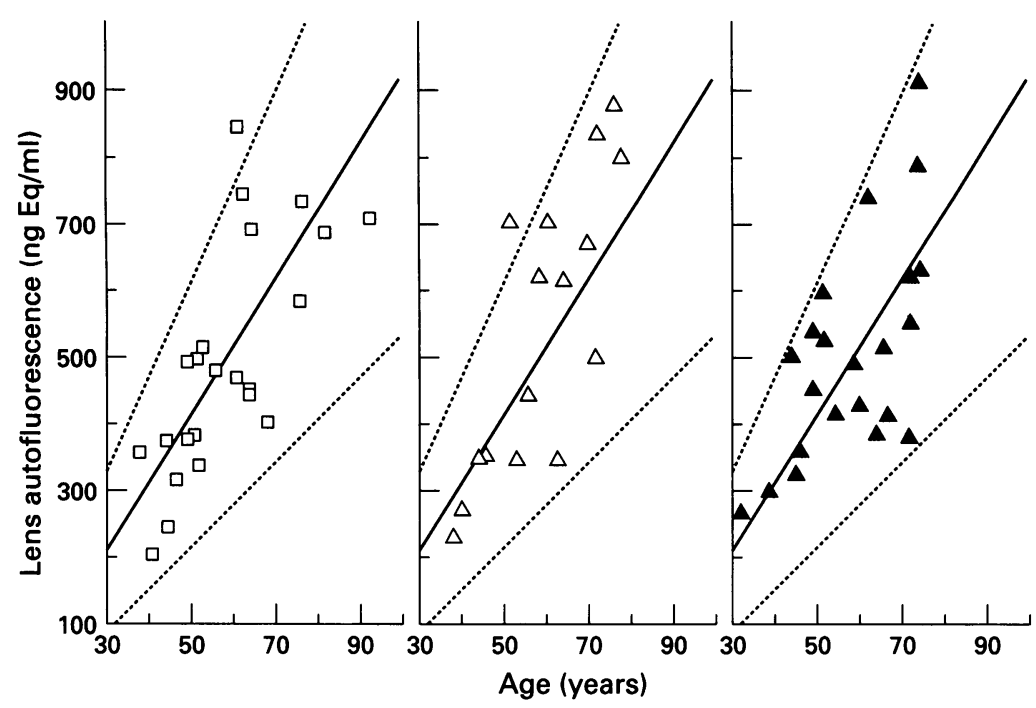

Figure 2 Lens autofluorescence as a function of age. The solid lines were obtained by weighted linear regression analysis to the values of healthy controls. Broken lines: $95 \%$ probability intervals for healthy controls. Left panel: healthy controls; middle panel: untreated primary open angle glaucoma patients; right panel: untreated ocular hypertension patients.

\section{Discussion}

The age dependency of lenticular autofluorescence values in healthy controls, POAG patients, and OHT patients were similar $(\mathrm{p}>0.5)$ and corresponded with those in previous studies. ${ }^{1318}$ The mean age normalised autofluorescence and light transmission values of POAG and OHT patients differed less than $5 \%$ from those of healthy controls $(p \geqslant 0 \cdot 2)$. This implies that both untreated POAG and $\mathrm{OHT}$ are not associated with an increased risk of developing cataract in the axial region of the lens. ${ }^{141719}$ Changes which develop outside this region may be overlooked in the measurements since fluorophotometry is based on scanning the eye in a small region along the optical axis.

The present results indicate that the IOP levels of our POAG and OHT patients do not significantly influence lenticular autofluorescence or transmission. Extremely elevated IOP levels (for example, $50-60 \mathrm{~mm} \mathrm{Hg}$ ), however, like those arising in attacks of acute glaucoma,

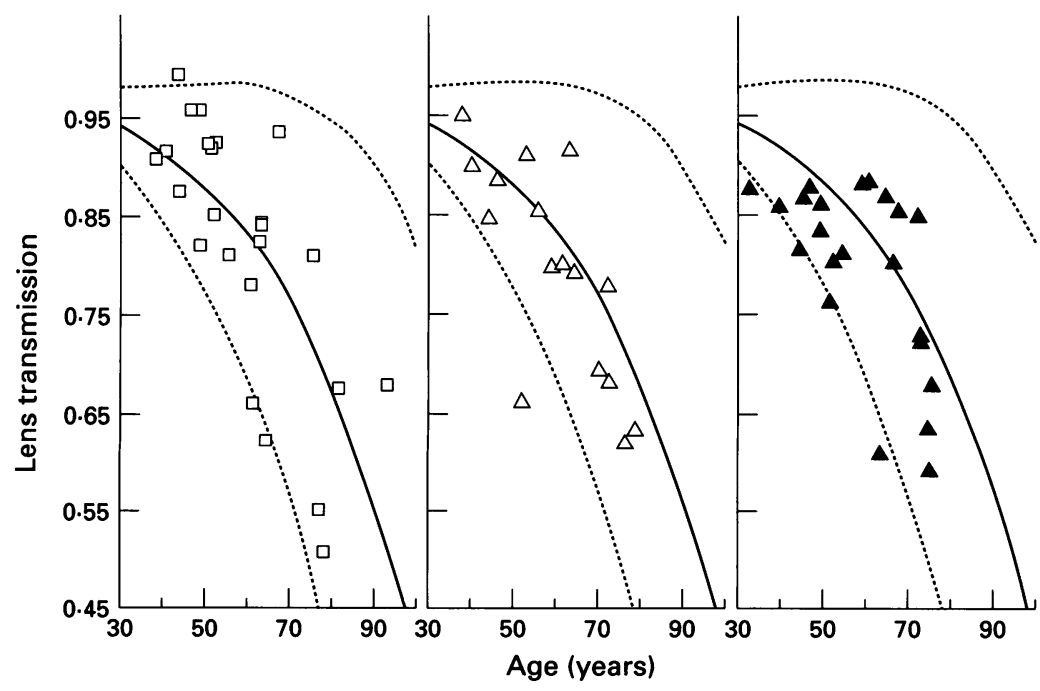

Figure 3 Lens transmission as a function of age. The solid lines were obtained by a least square approximation procedure to the values of healthy controls. Broken lines and panels as indicated in Figure 2 can induce cataract. ${ }^{20}$ The IOP levels of our POAG and OHT patients did not exceed $40 \mathrm{~mm} \mathrm{Hg}$ which may explain why IOP was not found to be a cataract inducing factor in this study.

Our findings are supported by those of Shaffer and coworkers ${ }^{4}$ who showed that the cataract incidence between a healthy population and a POAG population treated with pilocarpine or carbacholine only, did not differ significantly. They postulated that glaucoma in itself did not increase the probability of developing cataract. Additional evidence for our findings is provided by Van Buskirk ${ }^{21}$ who reported in 1982 that of the 1000 cases of timolol side effects registered over 3 years, only 12 concerned cataract.

On the other hand Harding and coworkers ${ }^{1}$ recently reported the analysis of two combined case-control studies: glaucoma was identified as a powerful and independent risk factor for cataract and was held responsible for $5 \%$ of all cataracts reported in England. However, this study concerned medically and/or surgically treated glaucoma patients which may have biased the study outcome.

As pointed out in several studies, ${ }^{3-9}$ there is evidence that both the medical and surgical treatment of glaucoma can cause cataract. Some of the topical antiglaucomatous medicaments such as strong miotics like echothiophate were held responsible for inducing cataracts in the past. ${ }^{36}$ The cataractous effect of frequently used miotics like pilocarpine is unclear: a previous study ${ }^{3}$ demonstrated that pilocarpine induced formation or progression of cataract in $10 \%$ of the POAG patients whereas another study ${ }^{4}$ did not supply evidence for such an effect. Surgical drainage procedures have been recognised as a contributing factor to the development of cataract $^{4-9}$ or merely as a cataract accelerating factor in patients who had already some cataract before surgery. ${ }^{22}$

It seems therefore plausible to assume that the treatment of glaucoma might increase the incidence of cataract in glaucomatous populations. This study shows that untreated POAG and OHT do not seem to increase the risk of developing cataract.

1 Harding JJ, Egerton M, van Heyningen R, Harding RS Diabetes, glaucoma, sex, and cataract: analysis of combined data from two case control studies. $\mathrm{Br} \mathcal{F}$ Ophthalmol 1993; 77: 2-6.

2 Van Heyningen R, Harding JJ. A case-control study of cataract in Oxfordshire: some risk factors. BrF Ophthalmol cataract in Oxford

3 Axelsson U, Holmberg A. The frequency of cataract after miotic therapy. Acta Ophthalmol 1966; 44: 421-9.

4 Shaffer RN, Rosenthal G. Comparison of cataract incidence in normal and glaucomatous population. Am $\mathcal{F}$ Ophthalmol 1970; 69: 368-70

5 Sugar HS. Postoperative cataract in successfully filtering glaucomatous eyes. Am f Ophthalmol 1970; 69: $740-6$.

6 Layden WE. Cataracts and glaucoma. In: Tasman W, Jaeger EA, eds. Duane's clinical ophthalmology. Rev ed. Philadelphia: Harper \& Row, 1979: 1-22.

7 Greve EL, Dake CL, Klaver JHJ, Mutsaerts EMG. Ten year prospective follow-up of a glaucoma operation. Int Ophthalmol 1985; 8: 139-46.

8 Harding J, Harding RS, Egerton M. Risk factors for cataract in Oxfordshire: diabetes, peripheral neuropathy, myopia, glaucoma and diarrhoea. Acta Ophthalmol 1989;
67: 510-7.

9 Laatikainen L. Late results of surgery on eyes with primary glaucoma and cataract. Acta Ophthalmol 1971; 49: 281-92. 
10 Flanagan DW. Diabetes, glaucoma, sex, and cataract. Br f Ophthalmol 1993; 77: 1 .

11 Lerman S, Borkman R. Spectroscopic evaluation and classification of the normal, aging and cataractous lens. Ophthalmic Res 1976; 8: 335-53.

12 Van Best JA, Tijn A Tsoi EWSJ, Boot JP, Oosterhuis JA. In vivo assessment of lens transmission for blue-green ligh by autofluorescence measurement. Ophthalmic Res 1985; 17: $90-5$.

13 Occhipinti JR, Mosier MA, Burstein NL. Autofluorescence and light transmission in the aging crystalline lens.

14 Mosier MA, Occhipinti JR, Burstein NL. Autofluorescence of the crystalline lens in diabetes. Arch Ophthalmol 1986; 104: 1340-3.

15 Bleeker JC, van Best JA, Vrij L, van der Velde EA Oosterhuis JA. Autofluorescence of the lens in diabetic and healthy subjects by fluorophotometry. Invest Ophthalmol Vis Sci 1986; 27: 791-4.

16 van Wirdum E, Mota MC, van Best JA, Leite E, Kappelhof
JP, Faria de Abreu JR, et al. Lens transmission and autofluorescence in renal disease. Ophthalmic Res 1988; 20: 317-26.

17 Yappert MC, Borchman D, Byrdwell WC. Comparison of specific blue and green fluorescence in cataractous versus normal human lens fractions. Invest Ophthalmol Vis Sci 1993; 34: 630-6.

18 Boets EPM, Kok JHC, van Best JA. The blue-green autofluorescence of the human ocular lens after the wear of PMMA contact lenses. Acta Ophthalmol 1994; 72: 67-71.

19 Siik S, Airaksinen PJ, Tuulonen A, Nieminen H. Autofluorescence in cataractous human lens. Invest Autofluorescence in cataractous human
Ophthalmol Vis Sci 1992; 33 (suppl): 1170.

20 Leydhecker W. Primäre Glaukomformen. In: Glaukom: ein Leydhecker W. Primäre Glaukomformen. In: Glaukom: ein
Handbuch. 2. Auflage. Berlin: Springer-Verlag, 1973: 20. 21 Van Buskirk EM. Hazards of medical glaucoma therapy in the cataract patient. Ophthalmology 1982; 89: 238-41.

22 Watson PG, Jakeman C, Ozturk M, Barnett MF, Barnett F, Khaw KT. The complications of trabeculectomy (a 20-year follow-up). Eye 1990; 4: 425-38. 